\title{
Novel Conception of a Tunable RF MEMS Resonator
}

\author{
Bassem Jmai \\ Department of physics, FST \\ Unit of Research in High Frequency \\ Electronic Circuits and Systems
}

\author{
Adnen Rajhi \\ Department of electrical engineering, \\ Carthage National School of \\ Engineering, Tunis, Tunisia \\ Laboratory of physics Soft materials \\ \& EM modeling
}

\author{
Ali Gharsallah \\ Department of physics, FST \\ Unit of Research in High Frequency \\ Electronic Circuits and Systems
}

\begin{abstract}
This paper presents a new monolithic microwave integrated circuit (MMIC) based on coplanar waveguide (CPW) design for a tunable resonator based on RF MEMS. This RF structure, which can be used for system on chip (SOC), is constituted with MEMS Bridge placed between two meander inductors and the tenability is controlled by a variable applied DC voltage. Moreover, this device presents a compactness characteristic and the possibility to operate at high frequencies. The resonant frequency and the bandwidth can be changed easily by changing the bridge gap of the RF MEMS. The numerical simulations of this novel structure of a tunable RF MEMS resonator were performed with the electromagnetic solvers CST MWS (Computer simulation Technology Microwave Studio) and validated by the more accurate electromagnetic solver HFSS (High Frequency Structural Simulator). The simulation results, for three different spacing of the bridge gap, show that the tunable frequency band are between 10 and $40 \mathrm{GHz}$ with the two electromagnetic solvers and exhibiting three resonant frequencies (21, 23.1 and 24.6 GHz).The simulation results of the return loss using CST achieves $29 \mathrm{~dB}$ with an insertion loss less than $1 \mathrm{~dB}$; However, the HFSS simulation shows similar performance in the resonant frequencies and in the bandwidth giving better results in terms of the return loss (about $35 \mathrm{~dB}$ instead of $29 \mathrm{~dB}$ ) and showing a good adaptation.
\end{abstract}

Keywords-RF MEMS; CPW; Meander inductor; Tunable; Resonator; MMIC

\section{INTRODUCTION}

The Micro-electromechanical system (MEMS) is a mixture of mechanical and electronic elements integrated on a common substrate. The MEMS component is characterized by the presence of suspended membranes of different geometry (beams, cantilevers, bridges, etc.), which allow the obtaining of a unique and very complex functionality [1]. The RF MEMS is used to replace the classical switch based on semiconductors in order to obtain a better RF performance [2].

The RF MEMS switches present several advantages compared to the conventional semiconductor components, such as, low insertion losses, good linearity, low power consumption, very important cut-off frequency, small volume and low fabrication cost [3]. However, the RF MEMS switches show some limitations, such as, the switching speed reduced to a few microseconds as a result of the mechanical structure movement [4].
Actually, the RF MEMS switches can be used in various domains: wireless communication, space, defense, security applications [5] and complex circuit. The radio frequency (RF) MEMS electrostatic actuators have been widely used in microwave communication system applications [6]. The majority of RF MEMS are operated through electrostatic force. This micro-electromechanical bridging element is employed to change the frequency.

According to the literature data, different tunable RF MEMS are commonly used to make a tunable inductor [7]-[8][9] or tunable capacitor [10]-[11]. Recently, many studies have combined both of the inductor and the capacity features [12][13]. However, their propose structures technologies in [12][13] based on variable capacitor and spiral inductor are very complicated on fabrication and configuration of the tunable RF-MEMS. The existence of the spiral inductor can create the radiation field which may affect the other components of the system.

In this paper, a novel structure design of monolithic reconfigurable resonator is presented and established. The proposed structure of RF MEMS resonator is based on a bridge with two meander self. The presented paper falls in three parts: section I presents a design of the classical RF MEMS and the simulation results, such as, the return loss, the insertion loss at different states. In section II and III, the proposed resonator is shown and described.

\section{THE CLASSICAL RF MEMS}

\section{A. Functioning principle}

This RF MEMS has a small dimensions (1200x900x681) $\mu \mathrm{m} 3$ and it is built with multilayer configuration as shown in figure 1.a. and figure 1.b illustrates the classical RF MEMS capacitor structure.

In order to analyze the $\mathrm{CPW}$ transmission lines, the characteristic impedance $\left(\mathrm{Z}_{\mathrm{C}}\right)$, and effective permittivity $\left(\varepsilon_{\text {eff }}\right)$ are analyzed in [14]-[15] and expressed by equations (1) and (2).

$$
\left\{\begin{array}{l}
Z_{C}=\frac{30 \pi}{\sqrt{\varepsilon_{\text {eff }}}} \frac{K^{\prime}(\mathrm{k})}{K(\mathrm{k})} \\
\varepsilon_{\text {eff }}=1+\frac{\varepsilon_{r}-1}{2} \frac{K^{\prime}(\mathrm{k}) K\left(\mathrm{k}_{1}\right)}{K(\mathrm{k}) K^{\prime}\left(\mathrm{k}_{1}\right)}+\frac{\varepsilon_{r 1}-\varepsilon_{r}}{2} \frac{K^{\prime}(\mathrm{k}) K\left(\mathrm{k}_{2}\right)}{K(\mathrm{k}) K^{\prime}\left(\mathrm{k}_{2}\right)}
\end{array}\right.
$$




$$
\left\{\begin{array}{c}
k=\frac{w}{w+2 s}, k_{1}=\frac{\operatorname{sh}\left(\frac{\pi w}{4 h}\right)}{\operatorname{sh}\left(\frac{\pi(w+2 s)}{2 h}\right)} \\
k_{2}=\frac{\operatorname{sh}\left(\frac{\pi w}{4 h_{1}}\right)}{\operatorname{sh}\left(\frac{\pi(w+2 s)}{2 h_{1}}\right)}
\end{array}\right.
$$

Where $\mathrm{K}(\mathrm{k})$ and $\mathrm{K}^{\prime}(\mathrm{k})$ present the complete elliptic integral essentially depending on their geometric and physical characteristic. $\varepsilon_{\mathrm{r}}$ is the relative permittivity, w is the width of the RF line, $s$ is the spacing between the RF Line and the ground, $\mathrm{h}$ is the height of the first silicon layer and $\mathrm{h} 2$ presents the second layer of silicon dioxide.

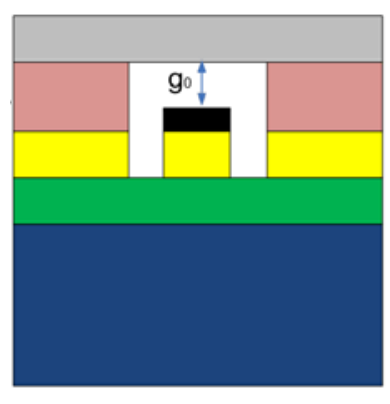

(a) Cross sectional view

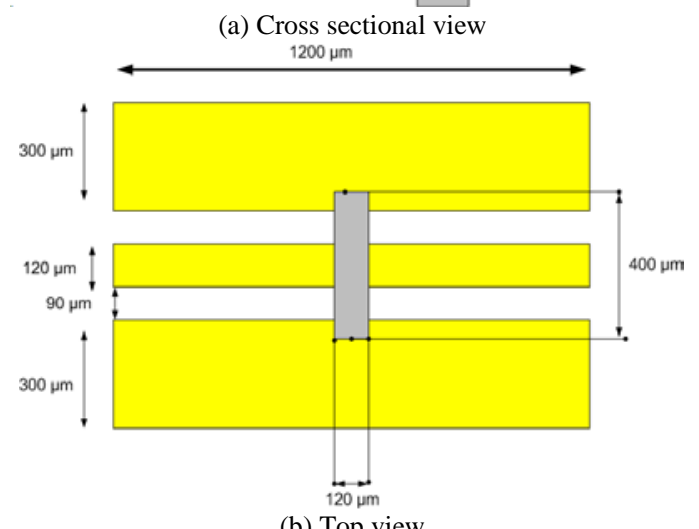

(b) Top view

Fig. 1. Design of RF-MEMS

In table I, geometrical and physical RF MEMS parameters are given. The substrate is based on silicon (Si) with thickness of $675 \mu \mathrm{m}$. The second layer is found with a silicon dioxide (SiO2) with thickness in order of $2 \mu \mathrm{m}$ and a CPW line circuit metal based at copper with thickness of $1 \mu \mathrm{m}$. The bridge is built with aluminum (Al) and with a depth of $1 \mu \mathrm{m}$. The extremities of the bridge are attached to the ground line of the CPW by an epoxy polymer based on negative-tone photo resist called SU-8 2000.5 with $3 \mu \mathrm{m}$ thickness. The dielectric has been fabricated with a silicon nitride (Si3N4) and with depth equal to $1 \mu \mathrm{m}$.

\begin{tabular}{|c|c|c|c|}
\hline & Material & Design parameter & Value \\
\hline Substrate & Si & Length*Width *Thickness $\left(\mu \mathrm{m}^{3}\right)$ & $1200 * 900 * 675$ \\
\hline $\begin{array}{l}\text { Buffer } \\
\text { layer }\end{array}$ & $\mathrm{SiO}_{2}$ & Length*Width *Thickness $\left(\mu \mathrm{m}^{3}\right)$ & $1200 * 900 * 1$ \\
\hline \multirow{2}{*}{ patch } & \multirow{2}{*}{$\mathrm{Cu}$} & Thickness of patch $(\mu \mathrm{m})$ & 1 \\
\hline & & CPW ligne $(\mathrm{G} / \mathrm{C} / \mathrm{G})(\mu \mathrm{m})$ & $90 / 120 / 90$ \\
\hline \multirow{4}{*}{ Dielectric } & \multirow{4}{*}{$\mathrm{Si}_{3} \mathrm{~N}_{4}$} & $\begin{array}{l}\text { Thickness of Dielectric layer } \\
(\mu \mathrm{m})\end{array}$ & 0.5 \\
\hline & & Width of Dielectric layer $(\mu \mathrm{m})$ & 120 \\
\hline & & Length of Dielectric layer $(\mu \mathrm{m})$ & 140 \\
\hline & & Width of Dielectric layer $(\mu \mathrm{m})$ & 120 \\
\hline \multirow{7}{*}{ Beam } & \multirow{7}{*}{$\mathrm{Al}$} & Thickness of bridge $(\mu \mathrm{m})$ & 1 \\
\hline & & Width of bridge $(\mu \mathrm{m})$ & 120 \\
\hline & & Length of bridge $(\mu \mathrm{m})$ & 400 \\
\hline & & Initial gap with RF line g0 $(\mu \mathrm{m})$ & 3 \\
\hline & & Young's modulus E (GPa) & 70 \\
\hline & & Poisson’s ratio & 0.35 \\
\hline & & Residual stress $\sigma(\mathrm{MPa})$ & 20 \\
\hline
\end{tabular}

TABLE I. DESIGNED PARAMETERS OF THE CAPACITIVE SWITCH

\section{B. Simulation results of RF characteristics}

Two electromagnetic software's (HFSS and CST MWS) are used and their computing methods are respectively the FEM method and the FIT method [16].

Figure 2 presents the obtained simulation results between $10 \mathrm{GHz}$ and $40 \mathrm{GHz}$ of the RF MEMS capacitive for three different conditions of the bridge.

The return loss and the insertion loss are presented in figure 2.a and b respectively, and the comparison between the two simulation results using two different simulator HFSS and CST illustrates a small variation $(<2.5 \mathrm{db})$.

Furthermore, the bandwidth of the capacitive MEMS for the three states $(g=2 \mu \mathrm{m}, 2.5 \mu \mathrm{m}, 3 \mu \mathrm{m})$, which is given for the S11 less than $-10 \mathrm{~dB}$, is obtained in the interval between $10 \mathrm{GHz}$ and $34 \mathrm{GHz}$. Beside this results, we observe a small variation of the resonant frequency.

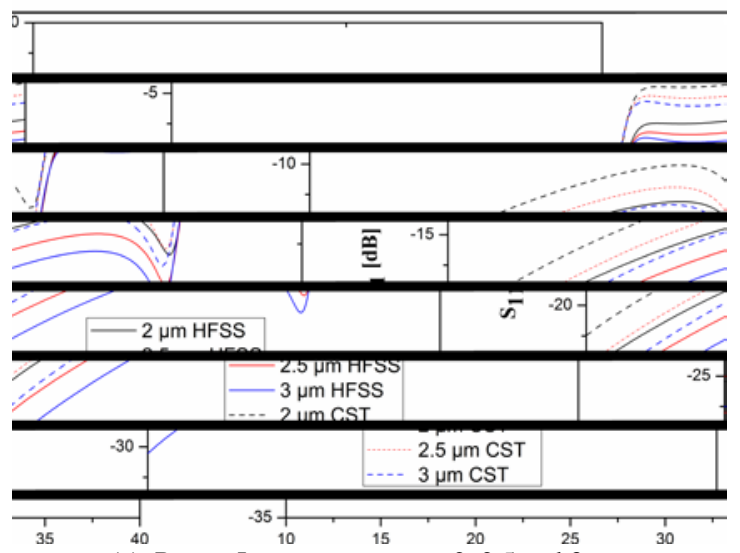

(a) Return Loss parameters at 2, 2.5 and $3 \mu \mathrm{m}$ 


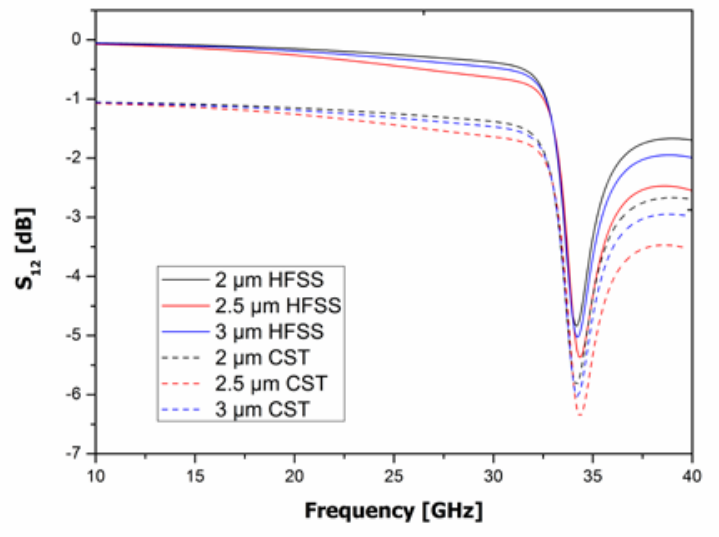

(b) Insertion Loss parameters at 2, 2.5 and $3 \mu \mathrm{m}$

Fig. 2. Simulation results of classical RF MEMS capacitive

\section{THE PROPOSED RF MEMS RESONATOR}

\section{A. Conception of the proposed resonator}

We know that there is an important claim of a reconfigurable radio-frequency component in the single-chip with high-performances and multiband characteristic as a solution for wireless communication [17], [18]. In this study, an improvement the capacitive RF MEMS structure is proposed in order to obtain a reconfigurable resonator. Figure 3 shows the suggested RF MEMS resonator structure. This component has the same dimension of the first one given in figure 1.a $(1200 \times 900 \times 681 \mu \mathrm{m} 3)$. Tow meander inductors are inserted in the RF lines with a length of $400 \mu \mathrm{m}$ and the width line of $10 \mu \mathrm{m}$.

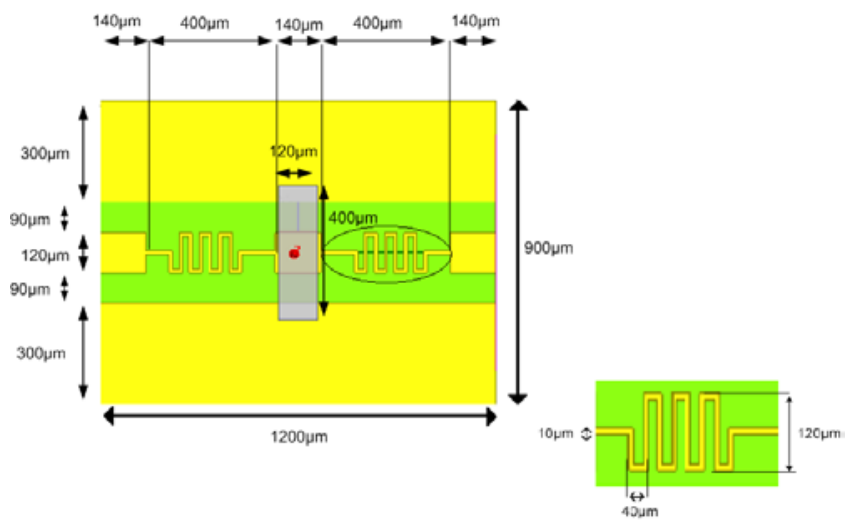

Fig. 3. Design of top view resonator RF-MEMS

The tunable RF MEMS function is based on capacitive and inductive effects. The capacitive effect is due to the space between the bridge and the RF line. While, the inductive effect is due to the presence of two meander inductors which are integrated in the RF lines. The combination of these two effects leads to a resonant phenomenon introducing different resonant frequencies. If the applied voltage $\mathrm{V}_{\mathrm{p}}$ is equal $0 \mathrm{~V}$, the bridge is in the UP state therefore the device is at a normally-ON state. Moreover, the spacing $g$ between the membrane bridge and the $\mathrm{RF}$ line affects the resonance frequency.

\section{B. RF Simulation results of the proposed resonator}

The proposed tunable resonator has been simulated by HFSS and CST-MWS simulators. Figure 4 present the scattering parameters for different bridge positions obtained on a frequency band between $10 \mathrm{GHz}$ and $40 \mathrm{GHz}$. The spacing $g$ among bridge and CPW line varies between $g=2 \mu \mathrm{m}$ at OFF state and $g=3 \mu \mathrm{m}$ at $\mathrm{ON}$ state.

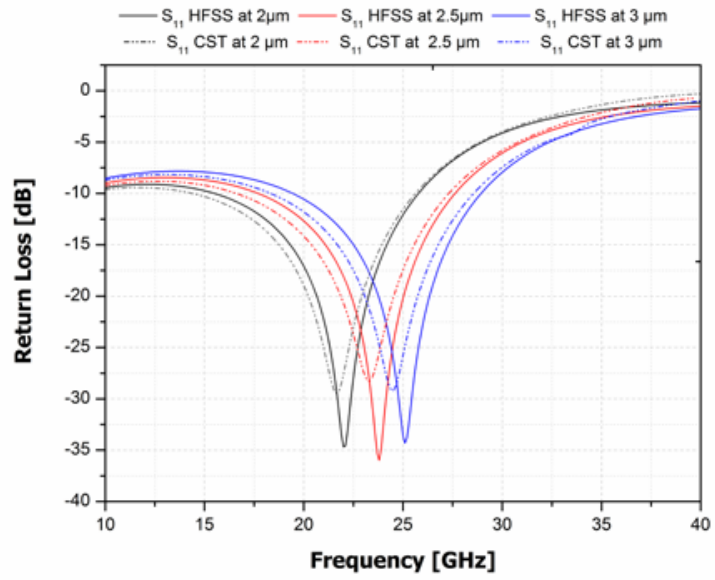

(a) Return Loss parameters at 2, 2.5 and $3 \mu \mathrm{m}$

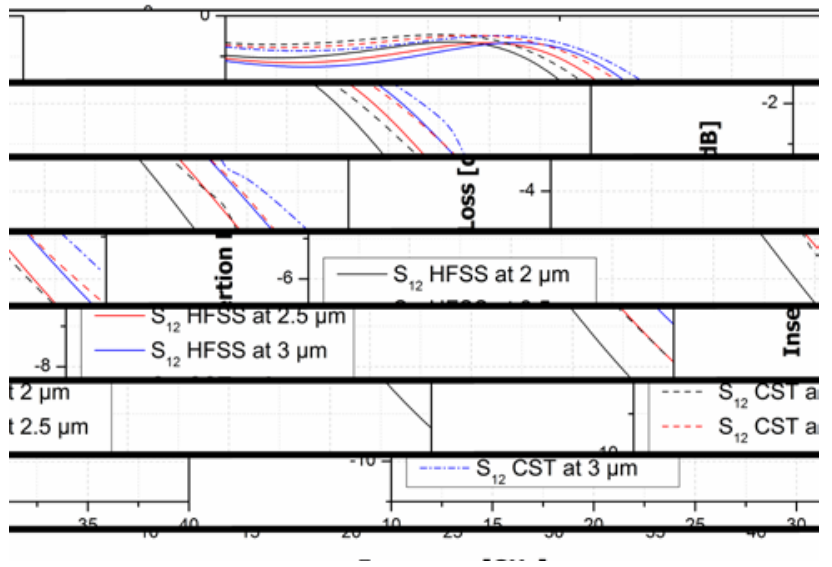

(b) Insertion Loss parameters at 2, 2.5 and $3 \mu \mathrm{m}$

Fig. 4. Scattering parameters at $g=2,2.5$ and $3 \mu \mathrm{m}$ : (a) Return Loss, (b)Insertion Loss

Figure 4.a and Figure 4.b are shown the return loss (S11) and the insertion loss (S12) respectively for $\mathrm{g}=2,2.5$ and $3 \mu \mathrm{m}$. The bridge variation level gives three resonances frequencies 21.9, 24 and $25.1 \mathrm{GHz}$.

The insertion loss S12 parameter presents almost constant value equal to $-1 \mathrm{db}$ for all simulated spacing $\mathrm{g}$ factor when the S11 parameter is down to $-10 \mathrm{db}$. There exists a good correspondence between the simulation results on HFSS and CST-MWS simulators.

\section{SiMUlation OF THE MECHANICAL CHARACTERISTICS}

The Pull-in voltage $\mathrm{V}_{\mathrm{p}}$ is an important parameter for RFMEMS switches; the relationship between the applied voltage and the spacing g parameter is given in [19] by the equation (3). 


$$
V p=\sqrt{\frac{2 k_{\mathrm{Z}}}{\varepsilon_{0} A} g^{2}\left(g_{0}-g\right)}
$$

The limit of the pull in voltage is at $g=(2 / 3) g_{0}$ which is given by equation (4).

$$
V p\left(g=\frac{2 g_{0}}{3}\right)=\sqrt{\frac{8}{27} \frac{k_{Z}}{\varepsilon_{0} A} g^{3}} .
$$

Where A is the contact area $\left(120^{*} 100\right) \mu \mathrm{m} 2, \varepsilon_{0}$ is the free space permittivity, $\mathrm{g}_{0}$ is the initial gap when $\left(\mathrm{V}_{\mathrm{p}}=0 \mathrm{~V}\right)$, $\mathrm{g}$ is the gap spacing when $\mathrm{V}_{\mathrm{p}}$ is activated $\left(0<\mathrm{g}<(2 / 3) \mathrm{g}_{0}\right)$ and $\mathrm{k}_{\mathrm{z}}$ is the spring constant of the aluminum bridge which is is found in [20] by the equation (5).

$$
k_{z}=\frac{1}{2}\left(32 E w\left(\frac{t}{l}\right)^{3}+8 \sigma(1-\vartheta) w\left(\frac{t}{l}\right)\right) .
$$

Where E is the Young's Modulus of Aluminum (69GPa), $\sigma$ is the residual stress of the beam, $v$ is the Poisson's coefficient $(v=0.345$ for Aluminum), $t$ is the thickness and 1 is the bridge length.

According to [19], for $g<(2 / 3)$ g0, the beam position becomes unstable; therefore it is not recommended to use these values of the gap spacing. Which introduces a planer capacitance with a value estimated by the following equation (6) given in [19]:

$$
\mathrm{C}=\frac{\varepsilon_{0} \mathrm{~A}}{\left(\mathrm{~g}_{0}-g\right)+\left(\mathrm{t}_{\mathrm{h}} / \varepsilon_{\mathrm{r}}\right)}
$$

Where $\mathrm{C}$ present the capacity shown between the bridge and the RF line, the $t_{h}$ and $\varepsilon_{\mathrm{r}}$ present the thickness and the relative permittivity of the dielectric respectively.

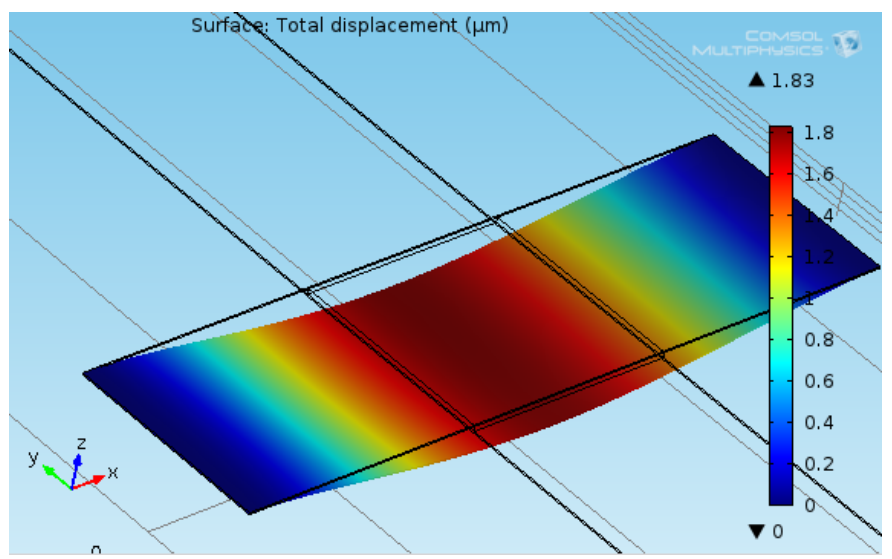

Fig. 5. Simulation results for the bridge $\mathrm{Vp}=37.4 \mathrm{~V}$

Simple beam model been conducted on comsol multiphysics based on FEM method [21]. After the defined the properties of bridge, the limit condition and meshing; the simulation result of the deflection for aluminum bridge given the pull in voltage $38,33.5$ and $0 \mathrm{~V}$ at the three levels state of the bridge (2, 2.5 and $3 \mu \mathrm{m})$. There is a correspondence between the result illustrates by comsol simulator and theoretical results. The figure 5 shows the simulation result of the deflection of the bridge at pull in voltage equal to $37.4 \mathrm{~V}$.

Table II summarizes the spacing $g$ factor versus the applied voltage calculated and simulated with Comsol. Then, the resonance frequency and the frequency range for different states of bridge are shown. This schedule contains a comparison of the simulation result between HFSS and CST. The proposed bandwidth able to covers 3 bands.

TABLE II. RF MEMS RESONATOR RESULTS

\begin{tabular}{|l|l|l|l|l|l|l|}
\hline \multirow{2}{*}{$\begin{array}{l}\text { Space } \\
(\boldsymbol{\mu m})\end{array}$} & \multicolumn{2}{|c|}{ Applied voltage (V) } & \multicolumn{4}{|l|}{ Cover band (GHz) } \\
\cline { 4 - 7 } & \multicolumn{2}{|l|}{$\begin{array}{l}\text { Resonance } \\
\text { frequency }\end{array}$} & \multicolumn{2}{l|}{$\begin{array}{l}\text { Frequencies } \\
\text { range }\end{array}$} \\
\cline { 2 - 7 } & Calculated & Comsol & HFSS & CST & HFSS & CST \\
\hline 2 & 36 & 38 & 21.9 & 21 & $\begin{array}{l}15.6- \\
25.7\end{array}$ & $\begin{array}{l}15- \\
25.7\end{array}$ \\
\hline 2.5 & 32 & 33.5 & 24 & 23.1 & $\begin{array}{l}17.8- \\
27.6\end{array}$ & $\begin{array}{l}17.6- \\
27.5\end{array}$ \\
\hline 3 & 0 & 0 & 25.1 & 24.6 & $\begin{array}{l}19.5- \\
29\end{array}$ & $\begin{array}{l}19.1- \\
28.9\end{array}$ \\
\hline
\end{tabular}

\section{DISCUSSION}

Table III summarizes the comparative study between the classical RF-MEMS and the proposed resonator between [10, $40 \mathrm{GHz}]$ in terms of the return loss and the insertion loss successively in table III (a) and table III (b).

TABLE III. COMPARATIVE STUDY BETWEEN RF MEMS CLASSICAL AND THE PROPOSED RESONATOR. [10- 40] GHZ

(A) COMPARATIVE IN TERMS OF RETURN LOSS LEVEL

\begin{tabular}{|l|l|l|l|l|l|}
\hline \multirow{2}{*}{$\begin{array}{l}\mathbf{R L} \\
\mathbf{( d B})\end{array}$} & \multirow{2}{*}{$\begin{array}{l}\text { Space } \\
\mathbf{g}(\boldsymbol{\mu m})\end{array}$} & \multicolumn{2}{|l|}{ Classical RF MEMS } & \multicolumn{2}{l|}{ Proposed resonator } \\
\cline { 3 - 6 } & & $\begin{array}{l}\text { Fmin } \\
(\mathrm{GHz})\end{array}$ & $\begin{array}{l}\text { Fmax } \\
(\mathrm{GHz})\end{array}$ & $\begin{array}{l}\text { Fmin } \\
(\mathrm{GHz})\end{array}$ & Fmax $(\mathrm{GHz})$ \\
\hline \multirow{3}{*}{$<(-10)$} & 2 & 10 & 34.8 & 15.6 & 25.7 \\
\cline { 3 - 6 } & 2.5 & 10 & 34.8 & 17.8 & 27.6 \\
\cline { 2 - 6 } & 3 & 10 & 34.8 & 19.5 & 29 \\
\hline \multirow{3}{*}{$<(-20)$} & 2 & 10 & 16.17 & 21 & 23 \\
\cline { 2 - 6 } & 2.5 & 10 & 18.04 & 22.9 & 25.6 \\
\cline { 2 - 6 } & 3 & 10 & 21 & 23.2 & 26 \\
\hline \multirow{3}{*}{$<(-30)$} & 2 & - & - & 21.5 & 22.3 \\
\cline { 2 - 6 } & 2.5 & - & - & 23.65 & 24.2 \\
\cline { 2 - 6 } & 3 & 10 & 10.2 & 24.7 & 25.6 \\
\hline
\end{tabular}

(B) COMPARATIVE IN TERMS OF INSERTION LOSS LEVEL

\begin{tabular}{|l|l|l|l|}
\hline \multirow{2}{*}{$\begin{array}{l}\text { IL } \\
(\mathbf{d B})\end{array}$} & \multirow{2}{*}{$\begin{array}{l}\text { Space } \\
\mathbf{g}(\boldsymbol{\mu m})\end{array}$} & Classical RF MEMS & Proposed resonator \\
\cline { 3 - 4 } & & Frequencies band $(\mathrm{GHz})$ & $\begin{array}{l}\text { Frequencies band } \\
(\mathrm{GHz})\end{array}$ \\
\hline \multirow{3}{*}{$>(-3)$} & 2 & {$[10-34]$ and [36-40] } & {$[10-29]$} \\
\cline { 2 - 4 } & 2.5 & {$[10-34]$ and [36-40] } & {$[10-32.5]$} \\
\cline { 2 - 4 } & 3 & {$[10-34]$ and [36-40] } & {$[10-34]$} \\
\hline
\end{tabular}

In the above obtained results, we observe that the RL of the classical RF MEMS does not have almost any values under -30 $\mathrm{dB}$; but for the proposed resonator has the less return loss, than $-30 \mathrm{~dB}$ is present in the bands [21.5-25.6 GHz]. Also, in terms of frequencies bands, we have a significant single usable ultrawide band [10-29 GHz] for the proposed resonator in spite of two frequency bands [10-29 GHz], [10-29 GHz] for the classical RF MEMS. 
The resonance aspect of the proposed resonator can be explained from table III (a) and III (b) of the insertion loss; in which we can see that the resonance occurs in the band [15.6$25.7 \mathrm{GHz}$ ] for $\mathrm{g}_{1}=2 \mu \mathrm{m}$ and in the band [17.8-27.6GHz] for $\mathrm{g}_{2}$ $=2.5 \mu \mathrm{m}$ and in the band $[19.5-29 \mathrm{GHz}]$ for $\mathrm{g}_{3}=3 \mu \mathrm{m}$.

Table IV summarizes the performances of different radio frequencies resonators using MEMS, metamaterials and RF diode. This proposed resonator based on RF MEMS with meander inductor can be tuned easily by changing the applied voltage, beside that the proposed resonator has a monolithic structure.

TABLE IV. DIFFERENT RADO FREQUENCY RESONATOR PERFORMANCES COMPARED TO THE PROPOSED ONE

\begin{tabular}{|l|l|l|l|l|l|}
\hline \multirow{2}{*}{ REF } & \multicolumn{4}{|l|}{ Structure Technology } & \multicolumn{3}{l|}{ Characteristics } \\
\cline { 2 - 6 } & Inductor & Capacity & $\begin{array}{l}\text { Frequencies } \\
(\mathrm{GHz})\end{array}$ & $\begin{array}{l}\text { Volume } \\
\left(\mathrm{mm}^{3}\right)\end{array}$ & $\begin{array}{l}\text { Complexit } \\
\mathrm{y}\end{array}$ \\
\hline$[13]$ & microstrip & diode & $1.7-2.2$ & $\begin{array}{l}43^{*} 51 * 0 . \\
762\end{array}$ & +++ \\
\hline$[15]$ & $\begin{array}{l}\text { CRR metamaterials } \\
+1 * \text { bridge }\end{array}$ & $25-42$ & $* * 0.280$ & +- \\
\hline$[22]$ & $2 *$ Spiral & $3 *$ bridge & $3-5.95$ & $21^{*} 21^{*} 2$ & ++ \\
\hline $\begin{array}{l}\text { This } \\
\text { Work }\end{array}$ & $2 *$ meander & $1 *$ bridge & $15-29$ & $\begin{array}{l}1.2 * 0.9 * 0 \\
.678\end{array}$ & -- \\
\hline
\end{tabular}

\section{CONCLUSION}

In this paper, we propose a new contribution for RF-MEMS to obtain a tunable resonator. The idea of this reconfigurable resonator is very simple, based on two meander inductors and a variable capacitance. The control of this capacitance is depending of the applied voltage to the bridge membrane applied. The simulation of this component is made by two commercial software and there are good correspondences between them at different spacing states of $\mathrm{g}(2,2.5$ and $3 \mu \mathrm{m})$. The obtained results for the three states $(2,2.5$ and $3 \mu \mathrm{m})$ are respectively 21.9, 24 and $25.1 \mathrm{GHz}$ for resonance frequencies. The bandwidths are [15.6, 25.7], [17.8, 27.6] and [19.5, 29] $\mathrm{GHz}$ respectively demonstrated for the three resonant frequencies $(|\mathrm{S} 11|=35 \mathrm{~dB}$ and $|\mathrm{S} 12|=1 \mathrm{~dB})$. This resonator switcher can be used in different RF applications for example at $\mathrm{K}$ and Ka bands.

\section{REFERENCES}

[1] A. Persano, F. Quaranta, M. Concetta, M. P. Siciliano and A. Cola, “On the electrostatic actuation of capacitive RF MEMS switches on GaAs substrate,” Sensors and Actuators A: Physical, vol. 232, pp. 202-207, August 2015.

[2] M. B. Kassem and R. Mansour, "High Power Latching RF MEMS Switches," IEEE transactions on microwave theory and techniques, vol. 63, pp. 222-232, January 2015.

[3] S. Yang, Ch. Zhang, H. E. Pank, A. Fathy and V. Nair, "Frequency reconfigurable antennas for multi radio wireless platforms," IEEE microwave magazine, vol. 10, pp. 66-74, February 2009.

[4] A. Verger, A. Pothier, C. Guines, A. Crunteanu, P. Blondy, J. C. Orlianges, J. Dhennin, A. Broue, F. Courtade and O. Vendier, "Sub- hundred nanosecond electrostatic actuated RF MEMS switched capacitors,” Journal of Micromechanics and Microengineering, vol. 20, pp. 1-7, June 2010.

[5] Sh. Bint Reyaz, C. Samuelsson, R. Malmqvist, S. Seok, M. Fryziel, P. A. Rolland, B. Grandchamp, P. Rantakari and T. Vaha-Heikkila , "Wband RF MEMS dicke switch networks in a GaAs MMIC process," Microwave and optical technology letters, vol. 55, pp. 2849-2853, December 2013.

[6] M. k. Yoon, J. P. Hyoung and J. P. Yeong, “Actively formed gold dual anchor structures-based RF MEMS tunable capacitor,” Microwave and optical technology letters vol. 57, pp. 1451-1454, June 2015.

[7] T. Ross, Kh. Hettak, G. Cormier and J.S. Wight, "Improved-Q inductors using airbridges for GaN phase shifters,” microwave and optical technology letters. 57(6): pp. 1455-1459, June 2015.

[8] S. Gholamian and E. A. Sani,"Design and Simulation of RF MEMS Tunable Spiral Inductor,” Advanced Materials Research 2012, vol. 403408: pp. 4148-4151, 2012.

[9] P. Branchi, L. Pantoli, V . Stornelli, G. Leuzzi, "RF and microwave high-Q floating active inductor design and implementation," International journal of circuit theory and applications, vol. 43, pp.10951104, August 2015.

[10] L. Gu, Z. Wu, and X.. Li, "Post-CMOS micromachined nickel tunablecapacitors with a large tuning-range under low actuating voltage. Microwave and optical technology letters, vol. 50, pp. 2469-2472, September 2008.

[11] M. Salehi, "High-speed FSK modulator using switched-capacitor resonators," International journal of circuit theory and applications, vol. 44, pp. 780-790.

[12] F. Lin and M. R. Zadeh, "Tunable RF MEMS Filters: A Review. Encyclopedia of nanotechnology”, pp. 1-12, March 2015.

[13] X. G. Wang, Y. H. Cho and S. W. Yun, "A tunable combline bandpass filter loaded with series resonator. IEEE transaction on microwave theory Technique, vol.60, No.6, pp. 1569-1576, March 2012.

[14] R. Garg, I. Bahl and M. Bozzi, "Microstrip Lines and Slotlines full,” 3rd Edition (January 2016).

[15] Bu. Pradhan and Bh. Gupta, "Ka-band tunable filter using metamaterials and RF MEMS varactors,” Journal of microelectromechanical systems, vol. 24(5) : pp. 1453 - 1461, March 2015.

[16] B. Jmai, A. Rajhi, A. Gharsallah, "Software comparative study for RF power coupler," In 14h: Mediterranean Microwave Symposium (MMS2014) 2014, pp. 1-6, 2014.

[17] Y. H. Chun and J. Sh. Hong, "Electronically reconfigurable dual-mode microstrip open-loop resonator filter," IEEE microwave and wireless components letters, vol. 18, pp.449-451, July 2008.

[18] M. Rinaldi, Ch. Zuo, J. Vander Spiegel and G. Piazza, "Reconfigurable CMOS Oscillator Based on multifrequency AIN Contour-Mode MEMS Resonators," IEEE Transactions on electron devices, Vol. 58, pp. 12811286, May 2011.

[19] G. M. Rebeiz, "RF MEMS: Theory, Design, and Technology,” John Wiley \& Sons, Inc., Hoboken, New Jersey (March 2003).

[20] A. Chakraborty, BH. Gupta and B. K. Sarkar, Design, fabrication and characterization of miniature RF MEMS switched capacitor based phase shifter. Microelectronics Journal, Vol. 45, pp. 1093-1102, August 2014.

[21] S. B. Jani, M. K. Hanu Sai, Ch. A. Praharsha, P. H. Babu, V. Karthikeya, Y. Srinivas, D. R. Lakshmi and K. S. Rao, "Microcantilever Based RF MEMS Switch for Wireless Communication," Microelectronics and Solid State Electronics, vol. 5, pp. 1-6, 2016.

[22] C.-C Cheng, G.M Rebeiz, "High- 4-6-GHz suspended stripline RF MEMS tunable filter with bandwidth control," IEEE transaction on microwave theory Technique. Vol. 59, pp. 2469-2476, Ocotober 2011. 